\title{
Strategi Peningkatan Peringkat Perguruan Tinggi Versi Kemristekdikti (Studi pada Universitas Brawijaya)
}

\author{
Mochammad Rozikin \\ Universitas Brawijaya \\ mochrozikin@ub.ac.id \\ Maya Kurniawati \\ Universitas Brawijaya \\ maya_kurniawati@student.ub.ac.id \\ Khairunnisa Aliyyah \\ Universitas Brawijaya \\ aliyyahkhairunnisa@gmail.com
}

\begin{abstract}
The Ministry of Research, Technology and Higher Education has announced the results of ranking universities in Indonesia. Universitas Brawijaya has experienced ups and downs in ranking. During the period of 2015-2019, the best ranking of Universitas Brawijaya in the fifth recruitment in 2016. This study aims to formulate a series of optimization strategies for improving UB's rank. Research approach with qualitative methods and the literature review technique and focusing on several approaches to formulate strategy, which are Balanced Scorecard, SWOT, and SPACE. Retrieval of data with the method of observation and documentation. While data validation with Triangulation. The results of this study explained that the Balanced Scorecard, SWOT, and SPACE could be used to solve strategy formulation problems. There are eleven strategic steps to optimize and improve Universitas Brawijaya's ranking by following the indicators set by the Ministry of Research, Technology and Higher Education.
\end{abstract}

Keywords: University Ranking, Strategy Formulation, Balanced Scorecard, SWOT, SPACE

\section{Article Info}

\section{PENDAHULUAN}

Sejak tahun 2015, Kementerian Riset, Teknologi, dan Pendidikan Tinggi (Kemristekdikti) melakukan klasterisasi dan pemeringkatan perguruan tinggi yang berada di bawah pembinaannya. Kemudian hasilnya dipublikasikan untuk diketahui stakeholder Pendidikan Tinggi. Tujuan pemeringkatan ini antara lain untuk: 1) memetakan atau mengelompokkan perguruan tinggi di Indonesia; 2) meningkatkan kualitas perguruan tinggi dalam melaksanakan Tri Dharma Perguruan Tinggi secara terus menerus; 3) dasar dalam pembinaan perguruan tinggi 4) dasar penyusunan kebijakan oleh kementerian; dan 5) informasi kepada masyarakat tentang performa atau kinerja perguruan tinggi. Penilaian untuk penentuan klasterisasi dan 
pemeringkatan perguruan tinggi pada tahun 2019 didasarkan pada Output-Outcome Base. Aspek-aspek yang dinilai antara lain Kinerja Masukan dengan bobot sebesar $40 \%$ dan Kinerja Luaran dengan bobot sebesar $60 \%$. Indikator penilaian secara rinci dapat dilihat pada Tabel 1.

Pemeringkatan yang dilakukan oleh Kemenristekdikti tersebut didasarkan pada lima komponen utama, yaitu 1) kualitas SDM; 2) kualitas kelembagaan; 3) kualitas kegiatan kemahasiswaan; 4) kualitas penelitian dan pengabdian pada masyarakat; 5) kualitas inovasi.

Dalam perjalanannya, indikator klasterisasi perguruan tinggi tahun 2019 telah mengalami perubahan dari indikator klasterisasi pada tahun 2017 dan 2018. Tahun 2017, aspek-aspek yang dinilai untuk pemeringkatan ini antara lain sumber daya manusia dengan bobot $30 \%$, kelembagaan dengan bobot $28 \%$, kemahasiswaan dengan bobot $12 \%$, serta penelitian dan pengabdian kepada masyarakat sebesar $30 \%$. Sedangkan pada tahun 2018, aspek-aspek penilaian pemeringkatan antara lain sumber daya manusia dengan bobot $25 \%$, kelembagaan dengan bobot $28 \%$, kemahasiswaan dengan bobot $12 \%$, penelitian dan pengabdian kepada masyarakat dengan bobot $30 \%$, dan muncul tambahan aspek inovasi dengan bobot $5 \%$.

Tabel 1. Indikator Klasterisasi Perguruan Tinggi Indonesia 2019

\begin{tabular}{|c|c|c|c|}
\hline \multicolumn{2}{|c|}{ Kinerja Masukan (40\%) } & \multicolumn{2}{|c|}{ Kinerja Luaran (60\%) } \\
\hline Input $(15 \%)$ & Proses $(25 \%)$ & Output $(25 \%)$ & Outcome $(35 \%)$ \\
\hline $\begin{array}{c}\% \text { dosen berpendidikan } \\
\text { S3 }\end{array}$ & $\begin{array}{l}\text { Akreditasi institusi } \\
\text { BAN-PT }\end{array}$ & $\begin{array}{l}\text { Jumlah artikel ilmiah } \\
\text { terindeks per dosen }\end{array}$ & Kinerja inovasi \\
\hline $\begin{array}{c}\text { \% dosen dalam jabatan } \\
\text { Lektor Kepala dan Guru } \\
\text { Besar }\end{array}$ & $\begin{array}{l}\text { Akreditasi program } \\
\text { studi BAN-PT }\end{array}$ & Kinerja penelitian & $\begin{array}{c}\text { \% lulusan yang memperoleh } \\
\text { pekerjaan dalam waktu } 6 \\
(\text { enam) bulan } *)\end{array}$ \\
\hline $\begin{array}{c}\text { Rasio jumlah } \\
\text { mahasiswa terhadap } \\
\text { dosen }\end{array}$ & Pembelajaran Daring *) & Kinerja kemahasiswaan & Jumlah sitasi per dosen $*$ ) \\
\hline $\begin{array}{l}\text { Jumlah mahasiswa } \\
\text { asing }\end{array}$ & $\begin{array}{c}\text { Kerjasama perguruan } \\
\text { tinggi }\end{array}$ & $\begin{array}{l}\text { Jumlah program studi } \\
\text { terakreditasi } \\
\text { internasional }\end{array}$ & Jumlah paten per dosen $*$ ) \\
\hline Jumlah dosen asing $*$ ) & $\begin{array}{l}\text { Kelengkapan Laporan } \\
\text { PDDIKTI *) }\end{array}$ & & $\begin{array}{l}\text { Kinerja pengabdian kepada } \\
\text { masyarakat } *)\end{array}$ \\
\hline & Laporan Keuangan *) & & \\
\hline
\end{tabular}

*) Indikator baru pada Klasterisasi Perguruan Tinggi Indonesia 2019

Sumber: Press Release Kemristekdikti 2019

Sesuai dengan data yang dihimpun dari Press Release Kemristekdikti, pada tahun 2019 klasterisasi dan pemeringkatan terhadap perguruan tinggi dibedakan menjadi dua kategori, yaitu perguruan tinggi non-vokasi dan perguruan tinggi vokasi. Di dalam perguruan tinggi non-vokasi terdapat lima klaster yang membagi 2.141 perguruan tinggi di Indonesia. Klaster 1 berjumlah 13 perguruan tinggi, klaster 2 berjumlah 70 perguruan tinggi, klaster 3 berjumlah 338 perguruan tinggi, klaster 4 berjumlah 955 perguruan tinggi, dan klaster 5 berjumlah 765 perguruan tinggi.

Sumber data di dalam penilaian pemeringkatan tahun 2019 yang dihimpun dari laman Kemristekdikti, diantaranya bersumber dari: 1) data PD Dikti (Pangkalan Data Pendidikan Tinggi); 2) data di luar PD Dikti tetapi merupakan hasil penilaian dari unit kerja kemristekdikti, seperti kinerja riset dan kinerja 
kemahasiswaan; 3) data di luar PDDIKTI yang dikumpulkan secara terstruktur oleh unit kerja dan relevan dengan pemeringkatan, seperti mahasiswa asing; dan 4) data eksternal Kemristekdikti yang menunjukkan kualitas perguruan tinggi, seperti data akreditasi dan publikasi terindeks Scopus.

Telah dijelaskan sebelumnya tujuan dari pemeringkatan ini salah satunya adalah sebagai penggerak sekaligus pendorong bagi perguruan tinggi untuk selalu meningkatkan daya saing, baik itu di tingkat nasional maupun tingkat internasional. Tujuan ini sejalan dengan arah pengembangan Universitas Brawijaya yang sedang merintis menuju perguruan tinggi World Class University (WCU). Dalam usahanya ini, Universitas Brawijaya telah menduduki peringkat versi Kemristekdikti mengalami naik-turun dari tahun ke tahun. Peringkat dan skor Universitas Brawijaya dapat dilihat pada Gambar 1 berikut.

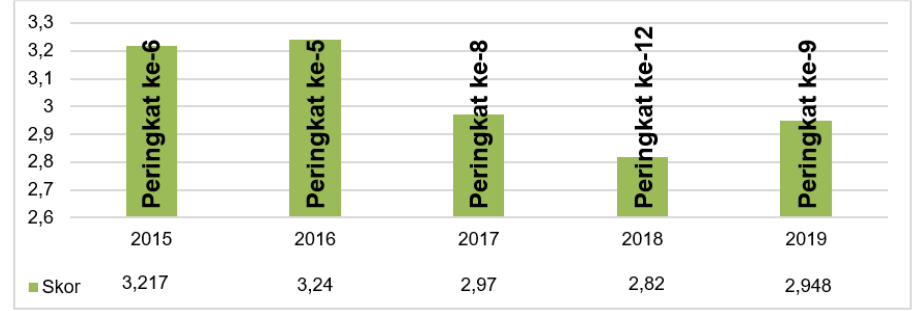

Sumber: Data yang dihimpun peneliti

\section{Gambar 1. Peringkat Universitas Brawijaya Versi Kemristekdikti Tahun 2015-2019}

Melihat peringkat Universitas Brawijaya yang berubah-ubah dari tahun ke tahun, bahkan sempat turun menjadi peringkat 12 di tahun 2018, maka perlu disusun sebuah strategi yang dapat mengoptimalkan dan meningkatkan peringkat Universitas Brawijaya di tingkat nasional sesuai dengan ketentuan Kemristekdikti tersebut. Oleh karenanya kajian strategi optimalisasi peningkatan peringkat diharapkan akan dapat membantu Universitas Brawijaya di skala nasional.

Peningkatan peringkat diperlukan sebagai nilai daya saing Universitas Brawijaya agar semakin unggul dan menjadi salah satu perguruan tinggi negeri yang berkualitas, baik itu secara nasional maupun internasional. Strategi peningkatan peringkat diperlukan karena visi pengembangan Universitas Brawijaya dalam Peraturan Rektor Universitas Brawijaya Nomor 53 Tahun 2018 tentang Rencana Strategis adalah menuju perguruan tinggi World Class University (WCU). Implementasi strategi perlu dikelola secara cepat dan tepat agar terlaksana dengan baik.
Penelitian ini bertujuan untuk merumuskan serangkaian strategi optimalisasi peningkatkan peringkat Universitas Brawijaya.

Manajemen strategi, adalah seni dan ilmu dalam, memformulasikan, mengevaluasi dan mengimplementasikan keputusankeputusan lintas fungsional dalam rangka pencapaian tujuan organisasi. Fokus dari manajemen strategi adalah menggabungkan pemasaran, produksi, keuangan, manajemen, pengembangan, penelitian, dan sistem informasi agar mewujudkan tercapainya kesuksesan organisasi.

Manajemen strategi mempunyai tiga proses tahapan, yaitu perencanaan (formulasi) strategi, pemberlakuan strategi, dan evaluasi strategi (David, 2011). Dalam tulisan ini lebih menitikberatkan pada perencanaan (formulasi strategi. Formulasi strategi adalah pembuatan visi dan misi, mengidentifikasi peluang dan ancaman eksternal pada organisasi, menentukan kekuatan dan kelemahan internal, yang bersifat jangka panjang dengan memberikan alternatif-alternatif strategi dan 
menentukan strategi untuk mencapainya. Disamping itu dalam formulasi strategi termasuk menentukan arah bisnis, jenis-jenis bisnis yang tidak perlu diteruskan, bagaimana mengalokasikan sumberdaya, apakah perlu memperbesar produksi atau membuat produksi lain, serta optimalisasi sumberdaya organisasi.

Semua organisasi memiliki sumber daya yang terbatas sehingga diperlukan keputusan dalam formulasi strategi yang dianggap paling menguntungkan bagi organisasi, apa yang perlu dikurangi dan apa yang perlu ditingkatkan (David, 2011). Sumberdaya organisasi lebih dikenal dengan 6M, 1I dan 1 T (man, money, method, material, machine, market), information and time. Ketersediaan sumberdaya organisasi tersebut terbatas sedangkan tujuan organisasi yang hendak dicapai sangat besar dan memerlukan dukungan stakeholder organisasi. Untuk itu langkah tepat dalam formulasi (perencanaan) stategi menjadi sangat penting sebagai parameter pelaksanaan tahap berikutnya.

Alat analisis yang banyak digunakan dalam menyusun rencana strategi (Renstra) adalah Balanced Scorecard (BSC) dan Strengths, Weaknesses, Opportunities, Threats (SWOT). Penggagas konsep balanced scorecard yaitu David Norton dan Robert
Kaplan di awal dekade 1990. Menurut Kaplan dan Norton dalam Niven (2008), sebuah organisasi seharusnya menyeimbangkan sistem pengukurannya. Contohnya ukuran keuangan perusahaan di masa lalu harus seimbang dengan performa keuangan organisasi saat ini dan masa depan. Konsep ini dianggap sederhana, sehingga kemudian populer digunakan di perusahaan-perusahaan di seluruh dunia. Balanced scorecard ini melakukan pengukuran dalam empat area, yaitu: proses bisnis internal, proses pelanggan, proses pembelajaran dan pengembangan, dan proses keuangan.

Balanced scorecard terdiri dari empat proses manajemen yang dapat dikombinasikan, dan dapat mendukung strategi jangka panjang (Kaplan \& Norton, 1996). Menurut Dally (2010), balanced scorecard kemudian dikembangkan secara lebih luas agar dapat menjadi cara berkomunikasi antar berbagai unit di dalam sebuah organisasi. Balanced scorecard juga dikembangkan menjadi alat yang dapat digunakan organisasi agar berfokus pada strategi, baik itu di organisasi bisnis maupun organisasi publik. Diagram perspektifperspektif dalam kerangka Balanced Scorecard yang berfungsi menginterpretasikan visi dan misi organisasi dapat dilihat pada Gambar 2.

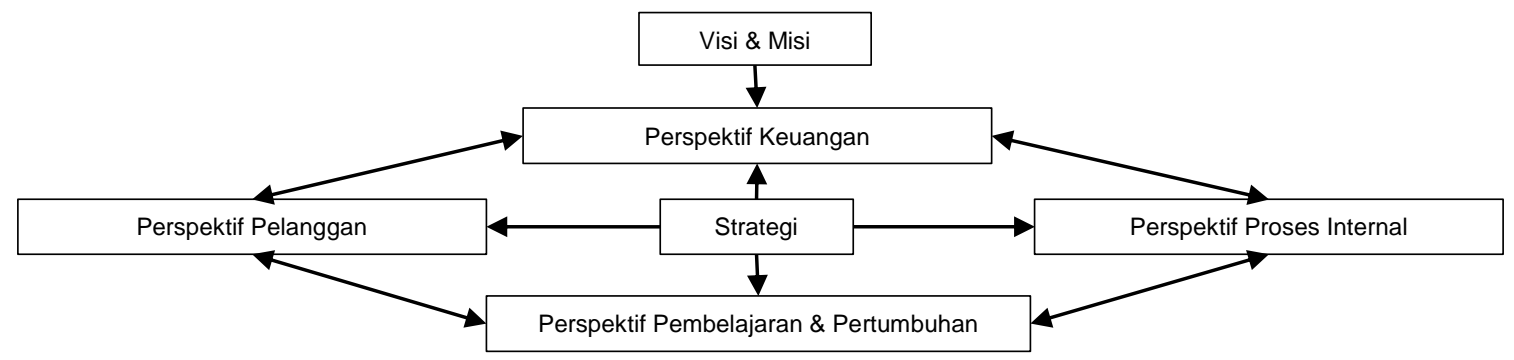

Sumber: Mahmudi (2005) dalam Rangkuti (2011)

Gambar 2. Diagram Perspektif Balanced Scorecard dalam Menginterpretasikan Visi dan Misi

Priyatno (2009) menjelaskan bahwa balanced scorecard adalah perangkat manajemen strategik bagi sebuah organisasi atau unit kerja yang dalam prosesnya digunakan untuk mencapai tujuan organisasi atau unit kerja tersebut dengan cara efektif dan efisien dengan menggunakan kemampuan untuk memantau atau memonitor baik secara keseluruhan maupun sebagian kegiatan, serta secepatnya melakukan tindakan koreksi, perbaikan atau penyempurnaan bila diperlukan. Tahapan-tahapan implementasi balance 
scorecard adalah sebagai berikut: 1) visi dan misi; 2) tujuan; 3) peta strategik; 4) bobot; 5) sasaran strategi; 6) Indikator Kinerja Utama (IKU); 7) program kerja, rencana kerja atau kinerja tahunan (RKT), atau menurut jangka waktu tertentu lainnya (strategic initiatives); 8) target; 9) realisasi; dan 10) skor. Balanced scorecard dengan demikian semakin berdayaguna. Dengan diintegrasikannya model analisis SWOT, Budaya Organisasi dan Manajemen Resiko serta berbagai modelmodel strategi lainnya, balanced scorecard ini dapat dipakai untuk mengelola kinerja dengan mempertimbangkan dari sisi faktor resiko dan strategi secara tepat (Rangkuti, 2011).

Sedangkan analisis SWOT (Strengths, Weaknesses, Opportunities, Threats) merupakan alat yang digunakan dalam menyusun perencanaan strategi (Renstra) atau digunakan manajemen strategi organisasi secara umum. Analisis SWOT dapat digunakan untuk membuat strategi organisasi dan strategi kompetitif (Gurel, 2017). Analisis SWOT secara lebih jelas dapat dilihat pada Gambar 3 berikut.

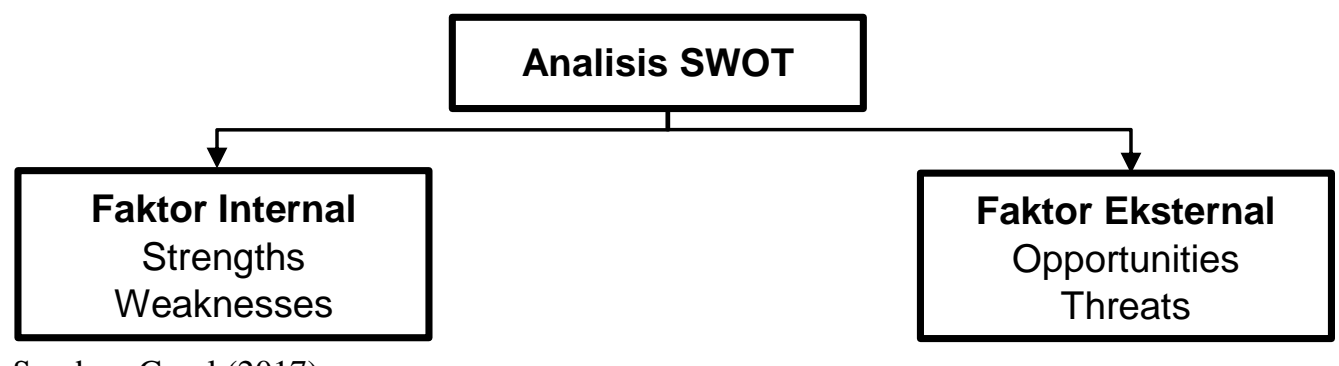

Sumber: Gurel (2017)

Gambar 3. Analisis SWOT

Matriks SWOT menurut Rangkuti (2011) dalam Ummi (2015), menggambarkan bagaimana peluang dan ancaman yang merupakan faktor eksternal dari organisasi dapat disesuaikan dengan kekuatan dan kelemahan yang dimiliki organisasi. Faktor eksternal dan internal tersebut dapat digunakan untuk memformulasikan strategi. Terdapat empat macam strategi yang dapat disusun menggunakan matriks SWOT, yaitu 1) Strategi SO yaitu Strengths-Opportunities; 2) Strategi WO yaitu Weaknesses-Opportunities; 3) Strategi ST yaitu Strengths-Threats; dan 4) Strategi WT yaitu Weaknesses-Threats. Strategi SO (Strengths-Opportunities) yaitu strategi yang mengerahkan seluruh kemampuan yang dimiliki dan menggunakannya untuk mendapatkan peluang. Strategi WO (Weaknesses-Opportunities) yaitu strategi yang dilakukan dengan menekan atau meminimalisir kelemahan dan lebih fokus pada peluang. Strategi ST (Strengths-Threats) yaitu strategi yang dilakukan dengan mengerahkan seluruh kekuatan yang dimiliki dan menggunakannya untuk mengatasi ancaman yang muncul. Strategi WT (Weaknesses-Threats) yaitu strategi yang dilakukan dengan cara menekan atau meminimalisir kelemahan dan berfokus dalam menghindari ancaman yang muncul (Rangkuti 2011). Penggambaran matriks SWOT secara sederhana terlihat pada Tabel 2.

Tabel 2. Matriks SWOT

\begin{tabular}{lcl}
\hline \multicolumn{1}{c}{ Internal Factor } & Strengths $-\mathbf{S}$ & Weaknesses $-\mathbf{W}$ \\
\hline Oxternal Factor & Strategi SO & Strategi WO \\
\hline Thportunities $-\mathbf{O}$ & Strategi ST & Strategi WT \\
\hline Sumber: Rangkuti (2011) & &
\end{tabular}


Dalam penelitian ini, digunakan pula metode Strategic Position and Action Evaluation (SPACE) yang merupakan alat yang digunakan pada penyusunan strategi. Metode ini menggunakan bagian internal (keunggulan kompetitif dan kekuatan finansial) serta bagian eksternal (kekuatan industri dan stabilitas lingkungan) dari organisasi (David, 2011). Sehingga matriks SPACE dapat juga digunakan untuk menganalisis faktor-faktor internal dan eksternal dari suatu organisasi dalam rangka formulasi strategi.

\section{METODE PENELITIAN}

Penelitian ini merupakan penelitian kualitatif yang mengkombinasikan dengan teknik literature review. Pengambilan data dalam penelitian ini dilakukan dengan metode observasi dan dokumentasi. Observasi yaitu salah satu teknik pengumpulan yang meningkatkan kemampuan peneliti untuk memahami situasi-situasi yang rumit. Observasi merupakan suatu alat yang kuat, observasi bisa bersifat terbuka maupun tertutup (undercover) (Ahmadi, 2014).

Observasi dan dokumentasi dilakukan dalam menentukan faktor-faktor internal dan eksternal yang mempengaruhi indikatorindikator klasterisasi dan pemeringkatan Kemristekdikti. Observasi dilakukan dengan melakukan pengamatan di Universitas Brawijaya. Observasi ini juga dikombinasikan dengan teknik dokumentasi dengan mengumpulkan dokumen-dokumen terkait faktor-faktor internal dan eksternal Universitas Brawijaya. Dalam literature review, dilakukan pencarian data dan informasi yang penting mengenai segala sesuatu yang berhubungan dengan penelitian bersumber dari penelitian, buku, e-book, dan lainnya yang berhubungan dengan strategi manajemen, formulasi manajemen, Balanced Scorecard, SWOT, dan SPACE. Untuk menguji validitas data, dilakukan teknik triangulasi terhadap sumber dan metode yang digunakan.

\section{HASIL PENELITIAN DAN PEMBAHASAN}

Perumusan strategi secara garis besar terbagi menjadi tiga tahap, yaitu identifikasi SWOT di Universitas Brawijaya (UB) dengan perspektif Balanced Scorecard, formulasi strategi dengan SPACE dan matriks SWOT, dan terakhir adalah penetapan langkah-langkah strategi dengan perspektif Balanced Scorecard. Pada tahap identifikasi SWOT di Universitas Brawijaya (UB) dengan perspektif Balanced Scorecard, dilakukan analisis terhadap faktorfaktor internal (Internal Factor Evaluation IFE) dan eksternal (External Factor Evaluation - EFE) dari Universitas Brawijaya (UB) yang berpengaruh terhadap dua puluh indikator klasterisasi dan pemeringkatan Kemristekdikti. Kemudian dilakukan tahap formulasi strategi menggunakan kombinasi matriks SPACE dan SWOT. Tahap terakhir yaitu tahap keputusan dengan menetapkan langkah-langkah strategi menggunakan perspektif Balanced Scorecard.

\section{Identifikasi SWOT dengan Perspektif Balanced Scorecard}

Tahapan ini diawali dengan mengklasifikasikan indikator-indikator pemeringkatan Kemristekdikti ke dalam perspektif Balanced Scorecard agar lebih sederhana menjadi empat area. Empat area tersebut adalah Keuangan, Pelanggan, Proses Internal, dan Pembelajaran dan Pertumbuhan. Pengklasifikasian indikator ke dalam perspektif Balanced Scorecard dilakukan dengan teknik brainstorming. Hasil klasifikasi dapat dilihat di Tabel 3. 
Tabel 3. Klasifikasi Indikator Klasterisasi dan Pemeringkatan Kemristekdikti dengan Perspektif Balanced Scorecard

\begin{tabular}{cccc}
\hline Keuangan & Pelanggan & Proses Internal & Pembelajaran \& Pertumbuhan \\
\hline $\begin{array}{c}\text { Laporan } \\
\text { Keuangan }\end{array}$ & Jumlah mahasiswa asing & $\begin{array}{c}\text { Rasio jumlah mahasiswa } \\
\text { terhadap dosen }\end{array}$ & $\%$ dosen berpendidikan S3 \\
\hline & Jumlah dosen asing & $\begin{array}{c}\text { Akreditasi institusi BAN- } \\
\text { PT }\end{array}$ & $\begin{array}{c}\text { \% dosen dalam jabatan Lektor } \\
\text { Kepala dan Guru Besar }\end{array}$ \\
\hline & Kerjasama perguruan tinggi & $\begin{array}{c}\text { Akreditasi program studi } \\
\text { BAN-PT }\end{array}$ & $\begin{array}{c}\text { Jumlah artikel ilmiah terindeks per } \\
\text { dosen }\end{array}$ \\
& $\begin{array}{c}\text { \% lulusan yang memperoleh } \\
\text { pekerjaan dalam waktu 6 } \\
\text { (enam) bulan }\end{array}$ & Pembelajaran Daring & Kinerja Penelitian \\
& & Kelengkapan Laporan \\
PDDIKTI & Kinerja inovasi \\
\hline & Kinerja kemahasiswaan & Jumlah sitasi per dosen \\
\hline & Jumlah program studi & Jumlah paten per dosen \\
\hline & terakreditasi internasional & Kinerja pengabdian kepada \\
& & masyarakat
\end{tabular}

Sumber: Hasil penelitian

Selanjutnya dilakukan identifikasi faktor-faktor internal dan eksternal Universitas Brawijaya sesuai dengan perspektif Balanced Scorecard melalui observasi dan dokumentasi. Observasi dilakukan dengan melakukan pengamatan di Universitas Brawijaya. Dokumentasi kemudian dilakukan dengan melihat dokumen-dokumen yang ada, baik itu secara online maupun offline untuk memastikan bahwa hasil observasi sudah sesuai. Tabel 4 hingga Tabel 7 menunjukkan hasil identifikasi SWOT pada setiap perspektif Balanced Scorecard, yaitu perspektif finansial, perspektif pelanggan, perspektif proses internal, serta perspektif pembelajaran dan pertumbuhan.

Tabel 4. Identifikasi SWOT pada Perspektif Finansial

\begin{tabular}{lll}
\hline SWOT & & Perspektif Finansial \\
\hline Strength & $\bullet$ & UB merupakan PTN BLU, sehingga otonom dalam mengelola dana PNBP, sehingga dapat \\
& menggunakan dana tersebut untuk mendirikan atau mengembangkan fasilitas perkuliahan \\
& $\bullet$ & $\begin{array}{l}\text { Dana universitas yang sumbernya dari APBN dan PNBP cukup besar, sehingga dapat diartikan } \\
\end{array}$ \\
& UB mandiri secara finansial \\
& & Terdapat banyak mahasiswa yang mendapatkan beasiswa yang bersumber dari PNBP maupun \\
& APBN (15\% dari keseluruhan mahasiswa jenjang S1) \\
\hline Weakness & $\bullet$ & Pendanaan bagi dosen UB masih kurang untuk kegiatan penelitian \\
\hline Opportunity & $\bullet$ & Pemerintah mengalokasikan anggaran yang cukup banyak untuk bidang pendidikan \\
& $\bullet$ & Terdapat cukup banyak institusi asing yang melakukan penawaran untuk dana penelitian \\
\hline Threat & $\bullet$ & Persyaratan yang semakin ketat diberikan oleh institusi ataupun pemerintah dalam memberikan \\
& & dana peneltiian dan pengabdian masyarakat \\
\hline Sumber: Hasil penelitian
\end{tabular}

Sumber: Hasil penelitian 
Strategi Peningkatan Peringkat Perguruan Tinggi Versi Kemristekdikti ... | Mochammad Rozikin, dkk.

Tabel 5. Identifikasi SWOT pada Perspektif Pelanggan

\begin{tabular}{|c|c|}
\hline SWOT & Perspektif Pelanggan \\
\hline Strength & $\begin{array}{l}\text { - Kerjasama dengan berbagai instansi telah dilakukan oleh UB, baik itu pihak pemerintah daerah, } \\
\text { pemerintah pusat, maupun swasta } \\
\text { - UB memiliki International Office sebagai fasilitas yang membantu mahasiswa asing dan dosen } \\
\text { asing yang melakukan kunjungan atau kuliah tamu }\end{array}$ \\
\hline Weakness & $\begin{array}{l}\text { - Kinerja Internasional Office masih kurang optimal dalam melakukan kerjasama internasional } \\
\text { dengan agen atau universitas luar negeri dalam rangka memperbanyak mahasiswa asing dan } \\
\text { visitasi dosen asing }\end{array}$ \\
\hline Opportunity & $\begin{array}{l}\text { - Alumni UB mendapat kesempatan yang besar untuk segera bekerja dengan banyaknya } \\
\text { lapangan kerja yang ada } \\
\text { - Semakin banyaknya mahasiswa asing yang memilih UB sebagai tempat melanjutkan } \\
\text { pendidikan }\end{array}$ \\
\hline Threat & $\begin{array}{l}\text { - Jumlah perguruan tinggi di Indonesia semakin banyak sehingga UB perlu meningkatkan daya } \\
\text { saing secara nasional dan internasional }\end{array}$ \\
\hline \multicolumn{2}{|c|}{ Sumber: Hasil penelitian } \\
\hline \multicolumn{2}{|r|}{ Tabel 6. Identifikasi SWOT pada Perspektif Proses Internal } \\
\hline SWOT & Perspektif Proses Internal \\
\hline Strength & - $\quad$ Akreditasi Institusi Perguruan Tinggi yang diraih UB berpredikat A (sangat baik) \\
\hline Weakness & $\begin{array}{l}\text { Persentase dosen UB yang memiliki jabatan Lektor Kepala adalah 15,89\% dan Guru Besar } \\
\text { adalah } 7,17 \% \text {, sehingga dapat dikatakan masih sedikit } \\
\text { - Apabila dilihat secara menyeluruh rasio jumlah dosen terhadap mahasiswa masih kurang, yaitu } \\
1: 28,12\end{array}$ \\
\hline Opportunity & $\begin{array}{l}\text { - Terdapat banyak lulusan jenjang SMA/ sederajat memiliki kemampuan akademik dan non- } \\
\text { akademik sangat baik yang dapat meningkatkan prestasi kemahasiswaan UB di tingkat nasional } \\
\text { dan internasional }\end{array}$ \\
\hline Threat & $\begin{array}{l}\text { - Sering terjadi perubahan regulasi oleh pemerintah pusat sehingga menyebabkan perubahan } \\
\text { regulasi yang mendasar di UB }\end{array}$ \\
\hline
\end{tabular}

Sumber: Hasil penelitian

Tabel 7. Identifikasi SWOT pada Perspektif Pembelajaran dan Pertumbuhan

\begin{tabular}{|c|c|}
\hline SWOT & Perspektif Pembelajaran dan Pertumbuhan \\
\hline Strength & $\begin{array}{l}\text { - Dosen UB yang jenjang pendidikannya S3 berjumlah } 775 \text { orang dan yang jenjang } \\
\text { pendidikannya Spesialis } 2 \text { berjumlah } 18 \text { orang, sehingga cukup banyak dosen-dosen yang } \\
\text { potensial }\end{array}$ \\
\hline Weakness & $\begin{array}{ll}\text { - } & \text { Dosen UB memiliki minat yang rendah dalam melakukan penelitian } \\
\text { - } & \text { Paten yang diperoleh dosen UB masih sedikit }\end{array}$ \\
\hline Opportunity & $\begin{array}{l}\text { - } \begin{array}{l}\text { Banyaknya kesempatan dari institusi asing untuk melakukan kerjasama dengan UB terkait } \\
\text { penelitian dan pengabdian kepada masyarakat }\end{array} \\
\text { - Terdapat banyak konferensi, seminar, atau kegiatan ilmiah lain yang menjadi sarana dosen UB } \\
\text { untuk mendesimenasikan penelitiannya baik nasional maupun internasional }\end{array}$ \\
\hline Threat & 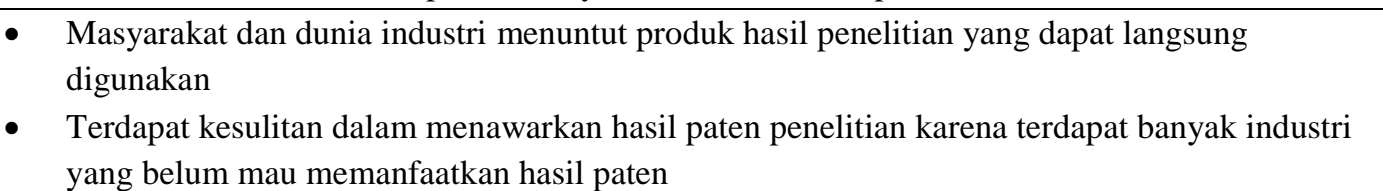 \\
\hline
\end{tabular}

Sumber: Hasil penelitian 


\section{Formulasi Strategi dengan SPACE dan} SWOT

Tahapan selanjutnya, teori yang digunakan adalah teori analisis SPACE yang diintegrasikan dengan SWOT. Matriks SPACE menggambarkan dua dimensi internal yaitu Financial Strength (FS) dan Competitive Advantage (CA) serta dua dimensi eksternal yaitu Environmental Stability (ES) dan Industry
Strength (IS). Matriks SWOT juga menggambarkan dua dimensi internal dan eksternal. Dua dimensi internalnya adalah Strength dan Weakness dan dua dimensi eksternalnya adalah Opportunity dan Threat. Kedua teori tersebut memiliki bentuk matriks yang mirip, sehingga apabila diintegrasikan terlihat seperti Gambar 4 berikut.

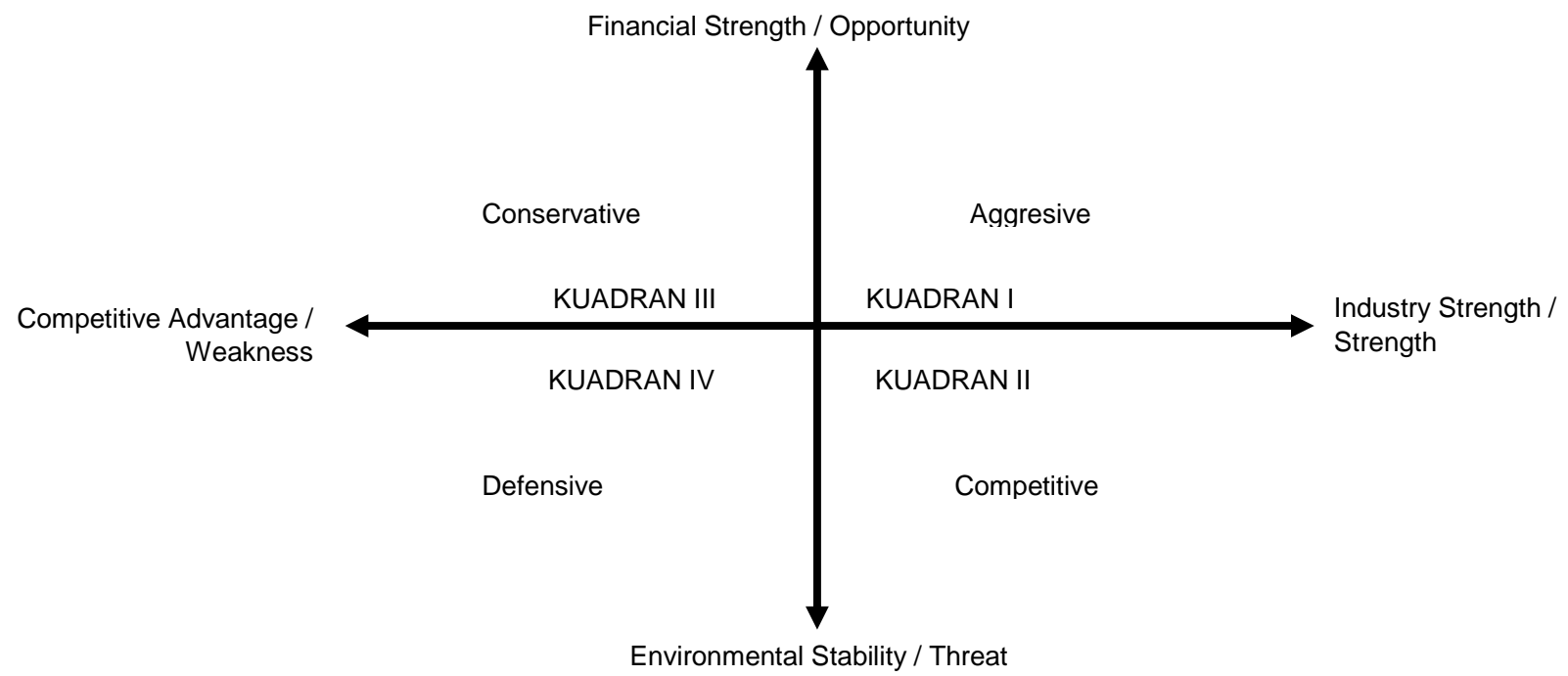

Sumber: Dihimpun oleh peneliti

\section{Gambar 4. Matriks SPACE dan SWOT}

Gambar 4 apabila dianalisis secara kualitatif dan dikaitkan dengan penyusunan strategi peningkatan pemeringkatan, maka akan sangat berkaitan dengan daya saing sebuah organisasi. Dengan kata lain, apabila ingin meningkatkan daya saing, maka perlu ditingkatkan sifat kompetitifnya. Hal ini terlihat pada Kuadran II matriks di atas. Sehingga, strategi yang disusun difokuskan pada strategi Strength dan Threat (Strategi ST). Strategi ST tersebut digambarkan pada Tabel 8. 


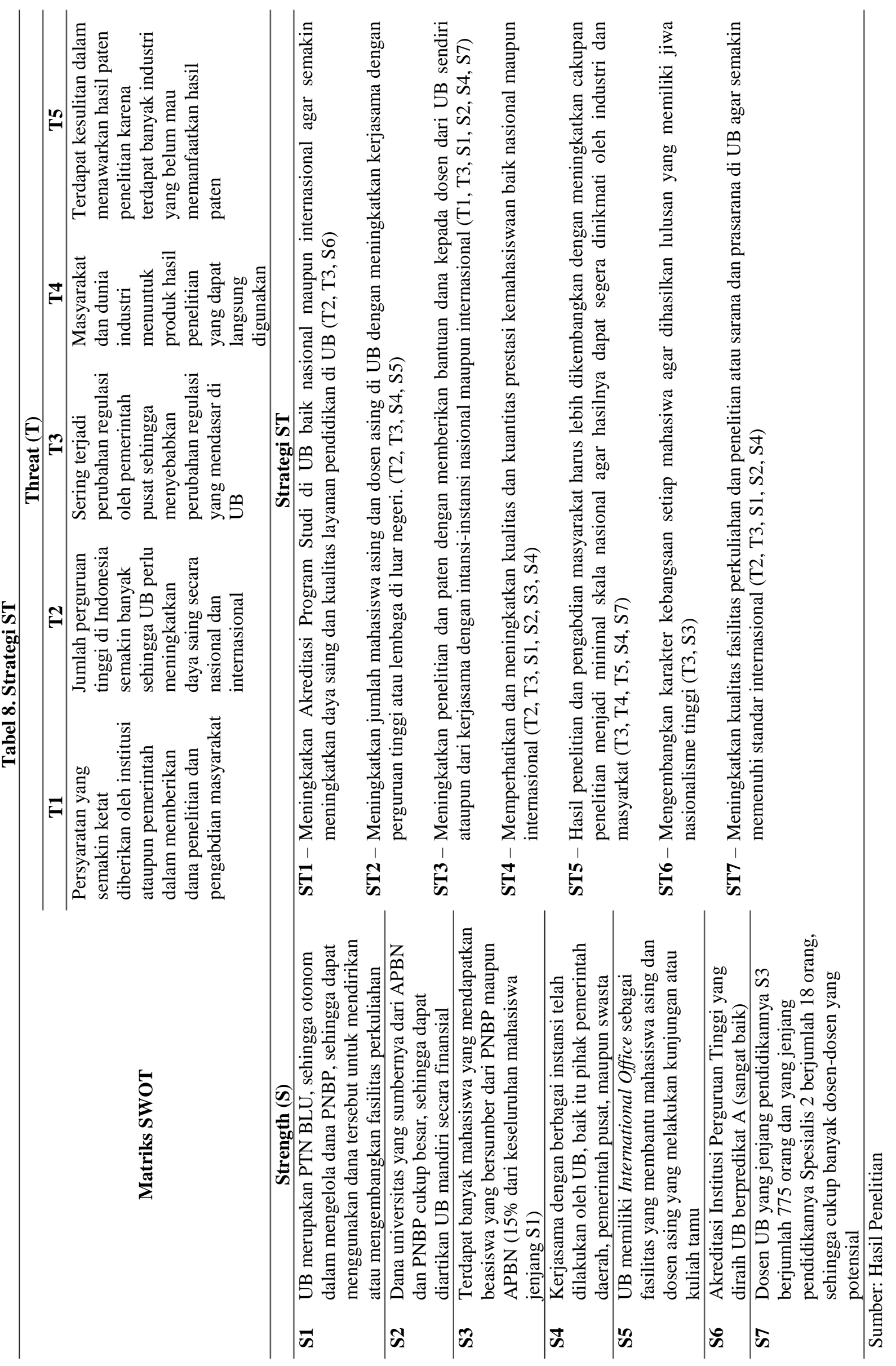


Penetapan Langkah-Langkah Strategi dengan Perspektif Balanced Scorecard

Pada tahapan ini, strategi ST yang sudah tersusun kemudian diklasifikasikan ke dalam perspektif Balanced Scorecard dan dilakukan penyusunan langkah-langkah strategi yang sebaiknya dilakukan oleh Universitas
Brawijaya agar dapat meningkatkan peringkatnya secara nasional. Langkah-langkah strategi tersebut merupakan hasil analisis dari strategi ST yang telah dihasilkan. Langkahlangkah strategi tersebut dapat dilihat pada Tabel 9.

Tabel 9. Langkah-Langkah Strategi dengan Perspektif Balanced Scorecard

\begin{tabular}{|c|c|c|}
\hline $\begin{array}{l}\text { Perspektif } \\
\text { Balanced } \\
\text { Scorecard }\end{array}$ & $\begin{array}{c}\text { Strategi } \\
\text { Peningkatan } \\
\text { Peringkat UB }\end{array}$ & Langkah-Langkah Strategi \\
\hline Finansial & ST3 & $\begin{array}{l}\text { - Melakukan kerjasama dengan instansi nasional dan internasional } \\
\text { terkait bantuan dana penelitian } \\
\text { - Meningkatkan bantuan dana penelitian kepada dosen, baik itu } \\
\text { bersumber dari UB sendiri maupun hasil kerjasama }\end{array}$ \\
\hline Pelanggan & ST2, ST4, ST6 & $\begin{array}{l}\text { - International Office meningkatkan kerjasama dengan lembaga dan } \\
\text { perguruan tinggi lain di luar negeri } \\
\text { - Memberikan reward kepada mahasiswa-mahasiswa yang berprestasi } \\
\text { akademik dan non-akademik } \\
\text { - Meningkatkan kualitas dan kuantitas mahasiswa yang berprestasi } \\
\text { secara nasional dan internasional } \\
\text { - Membuat kurikulum yang menanamkan nilai-nilai karakter } \\
\text { kebangsaan agar tercipta lulusan yang nasionalismenya tinggi }\end{array}$ \\
\hline Proses Internal & ST1, ST7 & $\begin{array}{l}\text { - Meningkatkan akreditasi seluruh program studi di UB, agar bisa } \\
\text { keseluruhan terakreditasi A } \\
\text { Program studi yang telah terakreditasi A secara nasional, dilanjutkan } \\
\text { dengan proses akreditasi internasional } \\
\text { - Meningkatkan kualitas layanan pendidikan dengan menambah dan } \\
\text { membenahi sarana dan prasarana yang ada agar bertaraf } \\
\text { internasional }\end{array}$ \\
\hline $\begin{array}{l}\text { Pembelajaran \& } \\
\text { Pertumbuhan }\end{array}$ & ST3, ST5 & $\begin{array}{l}\text { - Meningkatkan hasil penelitian dan paten yang dapat dimanfaatkan } \\
\text { oleh masyarakat dan industri } \\
\text { Meningkatkan kualitas dan kuantitas penelitian dan paten yang } \\
\text { berskala nasional agar hasilnya dapat langsung dimanfaatkan oleh } \\
\text { bangsa dan negara }\end{array}$ \\
\hline
\end{tabular}

Sumber: Hasil penelitian

Penetapan langkah-langkah strategi yang telah disusun pada Tabel 9 diharapkan dapat menjadi salah satu alternatif yang dapat digunakan dalam mengoptimalkan dan meningkatkan peringkat Universitas Brawijaya dalam skala nasional sesuai dengan indikatorindikator yang telah ditentukan oleh Kemristekdikti.

\section{SIMPULAN DAN SARAN Simpulan}

Sesuai dengan hasil penelitian dan pembahasan, dapat ditarik kesimpulan bahwa metode Balanced Scorecard, SWOT, dan SPACE, dapat dikombinasikan dalam penyusunan formulasi strategi dan penetapan langkah-langkah dalam mengoptimalkan dan meningkatkan peringkat Universitas Brawijaya sesuai dengan indikator klasterisasi dan pemeringkatan yang disusun oleh Kemristekdikti. Sesuai hasil penelitian, setelah dilakukan analisis SWOT dan dianalisis dengan empat perspektif Balance Scorecard, telah didapatkan sebelas langkah strategi yang sebaiknya dilakukan Universitas Brawijaya sesuai dengan tujuan penelitian ini yaitu 
merumuskan serangkaian strategi optimalisasi peningkatkan peringkat Universitas Brawijaya.

\section{Saran}

Penelitian ini hanya berfokus pada pemeringkatan perguruan tinggi secara nasional menggunakan indikator-indikator klasterisasi dan pemeringkatan yang ditentukan oleh Kemristekdikti. Sehingga dalam penelitian selanjutnya, metode yang digunakan pada penelitian ini dapat diteliti kembali untuk penyusunan strategi pada pemeringkatan versi lainnya, seperti Webometrics, 4ICU, dan sebagainya. Selain itu, dapat juga menggunakan pendekatan metode penelitian lainnya seperti metode kuantitatif agar hasil yang didapat dapat terukur.

\section{DAFTAR PUSTAKA}

Ahmadi, Rulam. 2014. Metodologi Penelitian Kualitatif. Yogyakarta: Ar-Ruzz Media.

Dally, Dadang. 2010. Balanced ScoreCard: Suatu Pendekatan dalam Implementasi Manajemen Berbasis Sekolah. Bandung: PT Remaja Rosdakarya.

David, Fred R. 2011. Strategic Management: Concepts and Cases. New Jersey: Pearson Education, Inc.

Gurel, Emet \& TAT, Merba. 2017. SWOT Analysis: A Theoretical Review. The Journal of International Social Research 10(51), 994-1006. http://www.sosyalarastirmalar.com/cilt 10/sayi51_pdf/6iksisat_kamu_isletme/g urel_emet.pdf

Kaplan, Robert S. \& Norton, David P. 1996. Using The Balanced Scorecard as a Strategic Management System. Harvard Business Review, 75-85.

Kementerian Riset, Teknologi, dan Pendidikan Tinggi. 2019. Press Release Klasterisasi Perguruan Tinggi
Indonesia

Tahun

2019. https://kelembagaan.ristekdikti.go.id/in dex.php/2019/08/17/press-releaseklasterisasi-perguruan-tinggiindonesia-tahun-2019/. Diakses 16 November 2019.

Kementerian Riset, Teknologi, dan Pendidikan Tinggi. 2019. Klasterisasi Perguruan Tinggi Indoensia 2019. http://kopertis3.or.id/v5/wpcontent/uploads/R-Purwanto-SKlasterisasi-PT-2019.pdf. Diakses 1 Desember 2019.

Niven, Paul R. 2008. Balanced Scorecard Stepby-Step for Government and Nonprofit Agencies. New Jersey: John Wiley \& Sons, Inc.

Peraturan Rektor Universitas Brawijaya Nomor 53 Tahun 2018 tentang Perubahan atas Peraturan Rektor Nomor 48 Tahun 2015 tentang Rencana Strategis Universitas Brawijaya Tahun 2015-2019.

Priyatno, M. 2009. Kajian Manajemen Strategik. Jakarta: Pusdiklat Spimnas Bidang Kepemimpinan.

Rangkuti, Freddy. 2011. SWOT Balanced Scorecard: Teknik Menyusun Strategi Korporat yang Efektif plus Cara Mengelola Kinerja dan Risiko. Jakarta: PT Gramedia Pustaka Utama.

Ummi, Nurul \& Setiawan, Hadi. 2015. Penerapan Balanced Scorecard sebagai Dasar SWOT Analisis dalam Perancangan Strategi Pengembangan Divisi PPIC di PT. X. Seminar Nasional Teknik Industri Universitas Gadjah Mada, E92-E102. http://digilib.mercubuana.ac.id/manage r/t!@file_artikel_abstrak/Isi_Artikel_3 96277236994.pdf. 